\title{
Movement patterns and genetic diversity of wild and reintroduced common dormice, Muscardinus avellanarius
}

\author{
D.M. Naim ${ }^{1,2}$, S. Telfer ${ }^{3}$, S. Tatman ${ }^{4}$, S. Bird ${ }^{5}$, S.J. Kemp ${ }^{1,6}$ and P.C. Watts ${ }^{1}$ \\ ${ }^{1}$ Division of Integrative Biology, University of Liverpool, Liverpool, UK \\ ${ }^{2}$ School of Biological Sciences, Universiti Sains Malaysia, Penang, Malaysia \\ ${ }^{3}$ Institute of Biological and Environmental Sciences, University of Aberdeen, \\ Aberdeen, UK \\ ${ }^{4}$ Cheshire Wildlife Trust, Bickley Hall Farm, Malpas, UK \\ ${ }^{5}$ North of England Zoological Society, Chester Zoo, Upton-by-Chester, UK \\ ${ }^{6}$ International Livestock Research Institute, Nairobi, Kenya \\ Corresponding author: D.M. Naim \\ E-mail: darlinamdn@usm.my
}

Genet. Mol. Res. 13 (1): 167-181 (2014)

Received March 20, 2013

Accepted November 5, 2013

Published January 10, 2014

DOI http://dx.doi.org/10.4238/2014.January.10.8

\begin{abstract}
Movement is an important life history trait that can have an impact on local adaptation, and other evolutionary phenomena. We used a combination of nestbox survey data and genetic techniques (genotyping at 10 microsatellite loci) to quantify patterns of movement in common dormice Muscardinus avellanarius at two distinct sites in the UK: 1) Bontuchel (a natural population) and 2) Wych (captivebred individuals that were reintroduced to this site), over three consecutive years (2006-2008). Both methods revealed a consistent pattern of sex-biased movement (movements by adult males and females) in both populations that allowed isolation-by-distance genetic structure to develop within $1 \mathrm{~km}$. The similarity of data from captivebred and natural individuals indicated that ex situ programing has not significantly altered the natural movement behavior of common
\end{abstract}


dormice; consequently, the two populations could be managed with the same conservation strategies. We also found that the reintroduced dormice in Wych maintained relatively high levels of genetic diversity. This first report of movement patterns in reintroduced and natural populations of M. avellanarius combining genetic and field-survey data highlights the role of genetic studies in the investigation of ecological behaviour and for conservation management.

Key words: Movement; Conservation; Microsatellite; Genetic structure; Common dormouse

\section{INTRODUCTION}

Species' dispersal characteristics influence a range of fundamental demographic and evolutionary processes (Hanski, 1999; Clobert et al., 2001). Of particular relevance for conservation is the association between population persistence and dispersal (i.e., gene flow), since the latter, for example, impacts upon the rate of genetic erosion and concomitant inbreeding effects and/or loss of evolutionary potential (Saccheri et al., 1998; Ewing et al., 2008). Accordingly, much research effort has been directed towards quantifying the putative roles of various life-history traits and ecological factors that influence dispersal, such as landscape heterogeneity, matrix quality and resource distribution (Manel et al., 2003; Scribner et al., 2006). In this context, establishing species' natural patterns of movement can provide insights into factors that are critical for the maintenance of viable populations - information that should underpin decisions about in situ management of species (Lidicker and Patton, 1987).

One issue that has not been thoroughly examined is the movement behaviour of animals that have been reintroduced to natural habitats after captive-breeding. Reintroductions are appealing as they facilitate population restoration or augmentation of endangered or locally-extinct species without affecting the demography of other natural populations (Armstrong and Seddon, 2008; Bowkett, 2009). Under certain circumstances, however, captive-bred animals may face different types of genetic problems in captivity (see Robert, 2009), such as inbreeding depression (Ralls et al., 1988), genetic drift (Bryant and Reed, 1999), loss of genetic diversity (Neveu et al., 1998), and/or genetic adaptations to captivity that are deleterious in the wild (Frankham, 2008), possibly due to the small population size, the unnatural setting of captivity, artificial selection, or their interactions (Robert, 2009), which may limit or even prevent a particular behaviour from being learnt. While many studies have examined the viability of reintroduced animals, including whether they are capable of some movement and/or dispersal (Diefenbach et al., 2006; Ausband and Moehrenschlager, 2009), to our knowledge, no studies have explicitly determined whether reintroduced populations have retained their natural movement tendencies.

The common dormouse Muscardinus avellanarius is a cryptic, arboreal mammal that typically inhabits areas of deciduous forest that have a thick layer of scrub plants and underbrush (Bright et al., 2006). This species is distributed from the Mediterranean to southern Sweden, eastward to Russia and into parts of northern Asia Minor (IUCN, 2009) and reaches the northwest limit of its European range in the UK, where it can be found over much of southern England and in isolated patches in northern Wales (Morris, 2004). The detrimental effects of 
habitat loss and fragmentation on M. avellanarius populations have been highlighted in the UK, where this species has suffered a $64 \%$ decline in numbers (in a survey of 59 hedgerow sites) since the late 1970s (Bright et al., 2006). M. avellanarius is now regarded as a "Flagship Species" for nature conservation and a bioindicator of woodland quality (Bright et al., 2006), and consequently, this species was categorised as 'least concern' on the Red List (IUCN, 2009). In the UK, M. avellanarius is listed as a Schedule 5 species and was placed on the English Nature's Species Recovery Programme in 1992 (Morris, 2004; Bright et al., 2006; Mitchell-Jones and White, 2009).

Accordingly, a programme of captive-breeding and reintroductions was initiated in 1983 with the ultimate goal of restoring this species' UK distribution. By 2008, a total of 635 captive-bred dormice had been released in 16 reintroduction sites (Mitchell-Jones and White, 2009). Generally, reintroduced populations of M. avellanarius have appeared viable, with records of breeding and marked animals spreading into adjacent habitats (Mitchell-Jones and White, 2009). The latter observation is interesting as observations from tagged animals indicate that adult $M$. avellanarius are relatively sedentary - typically moving less than 500 $\mathrm{m}$ during their lifetime (Morris, 2004; Büchner, 2008; Juškaitis, 2008). Of course, these estimates of movement may suffer from the potential limitations associated with directly tracking animals (see e.g., Koenig et al., 1996; Broquet and Petit, 2009). Many researchers have used direct methods (e.g., capture-mark-recapture, radio-telemetry) to study movement and dispersal in common dormice (see e.g., Bright and Morris, 1992; Juškaitis, 2005; Büchner, 2008; reviews in Juškaitis, 2008; Juškaitis and Büchner, 2010), but no one has yet evaluated movement patterns and subsequent spatial genetic structure using genetic methods for the species. Moreover, with regard to observations of breeding in reintroduced populations, a molecular genetic characterisation is required to assess the wider success of a reintroduction programme (see Grenier et al., 2007).

The main aim of this study was, through a combination of field surveys and molecular genetic techniques: 1) to quantify and compare the movement pattern exhibited by $M$. avellanarius in a natural population with the movement behaviour exhibited by reintroduced individuals that were sourced from captive-bred animals. In addition, we 2) quantified sex-biased movement characteristics in this species and 3) determined the levels of genetic diversity in these natural and reintroduced study populations.

\section{MATERIAL AND METHODS}

\section{Sample collection}

M. avellanarius were monitored at two sites in the UK: 1) Bontuchel (Wales; 53.109364N; -3.370318W) and 2) Wych Valley (England; 52.994994N; -2.7745169W) for three consecutive years (2006-2008). The natural population at Bontuchel inhabits a large area $\left(0.55 \mathrm{~km}^{2}\right)$ of mixed broadleaves and conifers, which allows movement to be studied without potential confounding effects associated with small habitat size. The reintroduced animals at Wych Valley are the descendents of 29 and 24 captive-bred dormice that were released (in 1996 and 1997, respectively) into a patch $\left(0.19 \mathrm{~km}^{2}\right)$ of ancient woodland and native broadleaf trees. For monitoring, 250 and 230 nestboxes spaced at intervals of approximately 20-40 $\mathrm{m}$ were installed within a $0.41-\mathrm{km}^{2}$ area at Bontuchel and $0.15-\mathrm{km}^{2}$ area at Wych, 
with each nestbox being geolocated using a global positioning system (GPS). Nestboxes at Wych were sampled for one day in May, June, September, and October, while nestboxes at Bontuchel were inspected either in May, June, July, September, and October (in 2006) or in May, June, September, and October (2007-2008). Every captured dormouse was scanned for a microchip (i.e., had been caught previously), and then its sex, weight and approximate age were recorded. The age of juveniles was estimated according to the development of external features and body weight (Juškaitis, 2001). Dormice without microchips were anaesthetised and then chipped using 8-mm microchips. For genetic analyses, hair and buccal swab samples were collected.

Direct estimates of movement tendencies were calculated as the distance moved per month between capture locations (i.e., nestbox) for each sex and age class separately. For animals first caught as juveniles, the cumulative distances may incorporate some natal dispersal and subsequent movements within home ranges, whilst for animals first caught as adults the cumulative distances may only represent home range movements. As the principal aim of this study was to determine whether there were any significant differences in movement pattern between the sexes and populations, we first checked whether there were differences between these groupings in 1) the proportion of animals first caught when young and 2) the length of time between first and last capture.

\section{DNA extraction and genotyping}

Total genomic DNA was extracted from hair and buccal swab samples using CHELEX-100 (Walsh et al., 1991). All samples were genotyped at 10 polymorphic microsatellite loci (Naim et al., 2009) with each 10- $\mu$ L PCR mixture containing $75 \mathrm{mM}$ Tris$\mathrm{HCl}, \mathrm{pH} 8.8,20 \mathrm{mM}\left(\mathrm{NH}_{4}\right)_{2} \mathrm{SO}_{4}, 0.01 \%$ Tween $20,0.2 \mathrm{mM}$ of each dNTP, $3 \mathrm{mM} \mathrm{MgCl}{ }_{2}, 1$ $\mu \mathrm{L}$ extracted template DNA, 3 pmol of each primer, $10 \mu \mathrm{g}$ BSA and $1.25 \mathrm{U}$ DNA polymerase (ABgene, Epsom, UK). Thermal cycling conditions were $95^{\circ} \mathrm{C}$ for $3 \mathrm{~min}, 6 \mathrm{X}\left[95^{\circ} \mathrm{C}\right.$ for $30 \mathrm{~s}$, $\mathrm{Ta}{ }^{\circ} \mathrm{C}$ for $45 \mathrm{~s}$ and $72^{\circ} \mathrm{C}$ for $\left.45 \mathrm{~s}\right], 25 \mathrm{X}\left[92^{\circ} \mathrm{C}\right.$ for $30 \mathrm{~s}, \mathrm{Ta}{ }^{\circ} \mathrm{C}$ for $45 \mathrm{~s}$ and $72^{\circ} \mathrm{C}$ for $55 \mathrm{~s}$ ], where $\mathrm{Ta}$ is the locus-specific annealing temperature (Naim et al., 2009). PCR products were pooled, according to the fluorophore and the allelic size range, with a 500-bp (LIZ) size standard, then separated by capillary electrophoresis on an ABI3130 xl and sized using the GeneMapper software (Applied Biosystems).

\section{Genetic diversity}

MICROCHECKER ver. 2.2.3 (Van Oosterhout et al., 2004) was used to check for systematic genotyping errors (null alleles, large allele dropout and any miss-scoring of stutter peaks). Tests for linkage disequilibrium between all locus-pair combinations were carried out using GENEPOP ver. 3.1d (Raymond and Rousset, 1995). Deviations from Hardy-Weinberg equilibrium (HWE) conditions were quantified using FSTAT ver. 2.9.3.2 (Goudet, 2001) with 2000 permutations of alleles among individuals within samples. FSTAT was used to calculate allelic richness $\left(A_{\mathrm{R}}\right)$ standardised to 75 individuals, expected heterozygosity $\left(H_{\mathrm{E}}\right)$ and Wright's (1951) inbreeding coefficient $(f)$. All analyses were tested for each population (Bontuchel and Wych) in each year (2006-2008) and for all age classes (adults and juveniles). Sequential Bonferroni's corrections for $k$ multiple tests were applied where appropriate (Rice, 1989). 


\section{Temporal genetic variation}

Hierarchical analysis of molecular variance (AMOVA) (Excoffier et al., 1992) was used to partition the contribution to genetic diversity arising from spatial variation with that occurring between successive sampling periods. Total genetic diversity was partitioned between temporal groups, between populations and between individuals within populations at each study site using ARLEQUIN ver. 2.0 (Schneider et al., 2000).

\section{Movement patterns}

To examine whether the pattern of movement differed between sex (sex-biased movement), we calculated 1) $F_{\text {IS }}$ and 2) $r$ (Lynch and Ritland, 1999) for adults of both sexes for each year using the biased dispersal option in FSTAT ver. 2.9.3.2 (Goudet, 2001). $F_{\text {IS }}$ is Weir and Cockerham's (1984) estimator of within-population inbreeding, while $r=2 F_{\mathrm{ST}} /\left(1+F_{\mathrm{IT}}\right)$ (where $F_{\mathrm{ST}}$ and $F_{\mathrm{IT}}$ are measures of inbreeding due to differences between subpopulations and of individuals relative to the total population, respectively) and is a measure of average relatedness of individuals within a population. Sex-biased movement was also examined using the mean probability of an individual's assignment to a population $(m A I c)$ and the variance in the probability of assignment of an individual to a population ( $v A I c$ ) (Goudet et al., 2002). Individuals living in close proximity were expected to be more related on average than individuals taken from the whole population, and a positive AIc value indicates that the genotype is more likely to come from the sampled population (review in Lawson Handley and Perrin, 2007). Thus, if there is sex-biased movement, $r$ and $m A I c$ are lower in the dispersive sex, whereas $F_{\text {IS }}$ and $v A I c$ will be higher (Goudet et al., 2002). The significances of the estimators were determined using 10,000 randomisations. Since the sex-biased movement signal in biparental markers disappears with mating (Goudet et al., 2002), we omitted juveniles from the data.

\section{Spatial genetic structure}

Spatial genetic structure was examined by spatial autocorrelation (Hardy and Vekemans, 1999). SPAGeDi ver.1.2 (Hardy and Vekemans, 2002) was used to calculate the average kinship $\left(F_{\mathrm{IJ}}\right.$, Loiselle et al., 1995) relative to the whole data set between pairs of M. avellanarius separated by a range of increasing distance classes. To test for significant spatial genetic structure, spatial group locations were permuted 1000 times to generate $95 \%$ confidence intervals for multilocus kinship coefficients at each distance class. For all spatial statistics, Euclidean geographical distances between individuals were calculated from the GPS $x$ and $y$ coordinates and analyses were conducted separately on the basis of sex, age and sample year.

Finally, to determine whether there was immigration into the study sites, we conducted assignment tests to evaluate the proportion of first-generation immigrants among adults within each locality and for each sex separately using the GENECLASS2 ver. 2.0 program (Piry et al., 2004). Likelihood computation was performed using the frequency method and the statistic $L_{h}$ (i.e., likelihood computed from the population where the individual was sampled) as recommended when all source populations for immigrants have not been sampled (Paetkau et al., 2004). The probability of an individual being resident was then assessed using the Monte Carlo resampling procedure of Paetkau et al. (2004). Individuals with a probability of less than 0.05 were excluded as resident and assigned as unknown population. 


\section{RESULTS}

\section{Biological parameters}

The capture-mark-recapture data included a total of 508 and 212 captures in Bontuchel and Wych, respectively, corresponding to 174 (2006), 93 (2007) and 54 (2008) new dormice caught in Bontuchel and 51 (2006), 60 (2007), and 44 (2008) new dormice caught in Wych over the three sample years. From these samples, a total of 296 and 135 dormice were successfully genotyped in Bontuchel and Wych, respectively, corresponding to 50 juveniles and 246 adults in Bontuchel and 15 juveniles and 120 adults in Wych. The adult sex ratio did not differ significantly from unity at either site (Bontuchel, $\chi^{2}=2.22$, d.f. $=1, \mathrm{P}>0.05$; Wych, $\chi^{2}=0.39$, d.f. $=1, P>0.05$ ). There was no significant difference between sites in the proportion of males first caught as juveniles $\left(\chi^{2}=0.80\right.$, d.f. $\left.=1, \mathrm{P}>0.05\right)$ or the proportion of females first caught as juveniles $\left(\chi^{2}=1.62\right.$, d.f. $\left.=1, P>0.05\right)$. Similarly, there was no significant difference between the sites in the length of time between first and last capture in males first caught as juveniles (Kruskal-Wallis test value $\mathrm{H}=0.18$, d.f. $=1, \mathrm{P}>0.05$ ) or the length of time between first and last capture in females first caught as juveniles (Kruskal-Wallis $\mathrm{H}=$ 0.09 , d.f. $=1, \mathrm{P}>0.05$ ). Only 10 juveniles from Bontuchel (4 females, 6 males) and 9 juveniles from Wych ( 3 females, 6 males) were subsequently caught as adults. Note that the frequency of sampling at Bontuchel in year 2006 (5 times) was greater than in 2007 and 2008 (4 times per year), whereas the frequency of sampling at Wych was consistent across years (4 times).

\section{Movement of M. avellanarius}

On the basis of the field data, a similar sex-biased pattern of movement was evident at both the natural and the reintroduced site, with males moving further than the females (Figure 1). At Bontuchel, the average distance moved per month by (recaptured) adult females and males was $53.62 \pm 4.21 \mathrm{~m}$ and $64.17 \pm 6.13 \mathrm{~m}$, respectively, and at Wych the average distances moved by adults were $51.57 \pm 3.28 \mathrm{~m}$ (females) and $66.60 \pm 4.21 \mathrm{~m}$ (males). The difference in average distance moved between sexes was significant at both sites (Bontuchel; Mann-Whitney U-test: $n_{1} n_{2}=40,47, \mathrm{U}=773, \mathrm{P}<0.05$, Wych; Mann-Whitney U-test: $n_{1} n_{2}=$ $24,25, \mathrm{U}=383, \mathrm{P}<0.05)$; however, there was no significant difference in the average distance moved by dormice between the two sites for either sex (males, Mann-Whitney U-test: $n_{1} n_{2}=$ 40, 24, $\mathrm{U}=538, \mathrm{P}>0.05$; females, Mann-Whitney U-test: $n_{1} n_{2}=47,25, \mathrm{U}=459, \mathrm{P}>0.05$ ). The average period between the first and last capture for adult female dormice was not significantly different between sites (Bontuchel: $7.63 \pm 3.23$ months; Wych: $7.92 \pm 0.33$ months; Kruskal-Wallis $\mathrm{H}=0.05$, d.f. $=1, \mathrm{P}>0.05)$. Likewise, there was no significant difference between the first and last capture dates of male dormice (Bontuchel: $10.01 \pm 1.87$ months; Wych: $9.23 \pm 2.54$ months; Kruskal-Wallis $\mathrm{H}=1.62$, d.f. $=1, \mathrm{P}>0.05$ ). However, the average period between the first and last capture was significantly different between sexes at both sites (Bontuchel: Kruskal-Wallis $\mathrm{H}=4.20$, d.f. $=1, \mathrm{P}<0.05$; Wych: Kruskal-Wallis $\mathrm{H}=6.57$, d.f. $=1, \mathrm{P}<0.05$ ). There was no significant difference in the distance moved between first and last capture of males and females that were caught first as juveniles and later as adults at Bontuchel (Mann-Whitney U-test: $n_{1} n_{2}=6,4, \mathrm{U}=3, \mathrm{P}>0.05$ ) and at Wych (Mann-Whitney U-test: $n_{1} n_{2}$ $=6,3, \mathrm{U}=6.5, \mathrm{P}>0.05)$. 
A

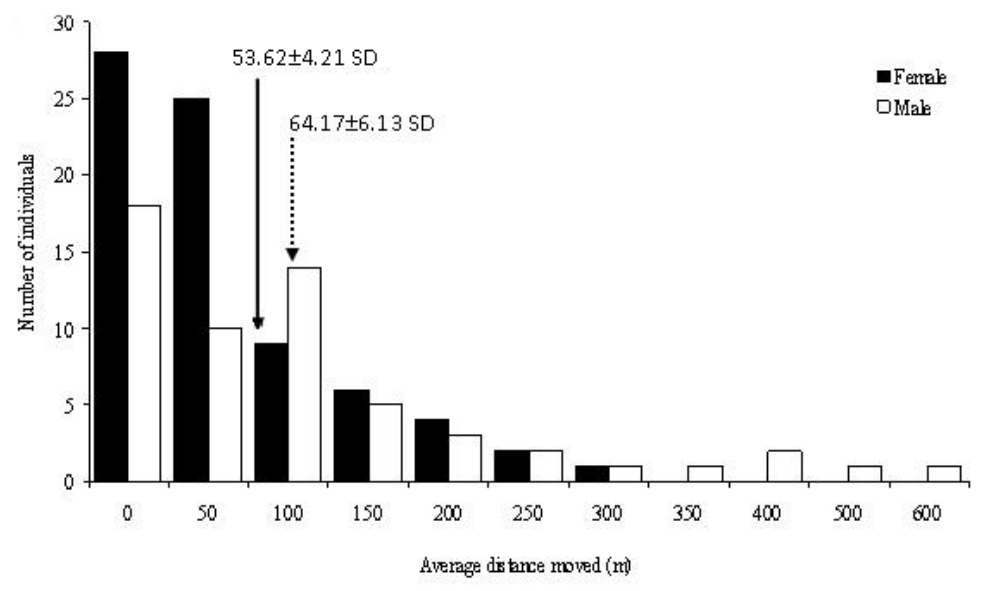

B

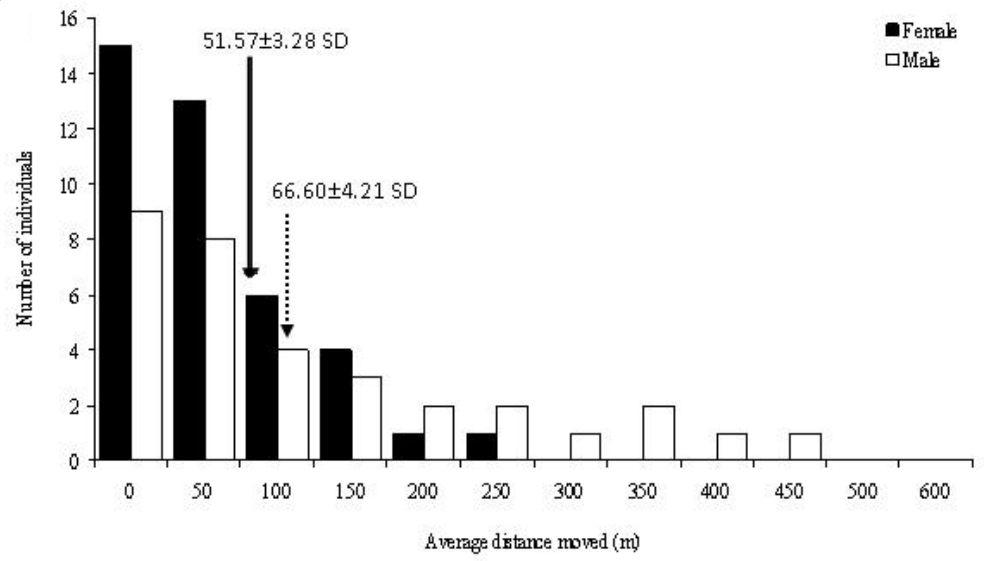

Figure 1. Distance moved per month of adult males and females of Muscardinus avellanarius in A. Bontuchel, and B. Wych. Arrows indicate the average distance moved by each sex.

\section{Genetic diversity}

None of the loci suffered from errors due to stuttering, large allele dropout or null alleles, and all ten microsatellite loci were polymorphic (Table 1). After sequential Bonferroni's correction, no locus deviated significantly $(\mathrm{P}>0.05)$ from expected HWE conditions and significant linkage disequilibrium was not found between any pair of loci. Genetic variability was greater at Bontuchel with number of alleles $\left(N_{\mathrm{A}}\right)$ per locus ranging between 6 and 14 compared with 5 to 11 alleles at Wych. Similarly, mean $A_{\mathrm{R}}$, was greater at Bontuchel (range: 8.60-9.30) than at Wych (range: 5.20-6.80) (Table 1). However, $H_{\mathrm{E}}$ at Bontuchel $\left(H_{\mathrm{E}}=0.691 \pm 0.01\right)$ and Wych $\left(H_{\mathrm{E}}=0.667 \pm 0.03\right)$ did not differ significantly between sites $(t$-test, $t=1.46$, d.f. $=4, \mathrm{P}$ $>0.05$ ) and was relatively constant over the three years of study. 
Table 1. Basic genetic diversity statistics of two common dormouse (Muscardinus avellanarius) populations.

\begin{tabular}{|c|c|c|c|c|c|c|c|c|c|c|c|c|c|}
\hline \multirow[t]{2}{*}{ Site } & \multirow[t]{2}{*}{ Year } & & \multicolumn{11}{|c|}{ Locus } \\
\hline & & & MavG3 & MavE3 & MavF10 & MavB5 & MavA5 & MavG6 & MavG9 & MavH3 & mavC4-2 & mavF1-2 & Average \\
\hline \multirow[t]{15}{*}{ Bontuchel } & \multirow[t]{5}{*}{2006} & $N_{\mathrm{A}}$ & 6.00 & 10.00 & 11.00 & 10.00 & 10.00 & 10.00 & 8.00 & 8.00 & 14.00 & 10.00 & 9.70 \\
\hline & & $H_{\mathrm{O}}^{\mathrm{A}}$ & 0.717 & 0.588 & 0.695 & 0.616 & 0.657 & 0.7551 & 0.798 & 0.581 & 0.717 & 0.657 & 0.678 \\
\hline & & $H_{\mathrm{E}}$ & 0.739 & 0.579 & 0.737 & 0.653 & 0.669 & 0.759 & 0.739 & 0.598 & 0.782 & 0.732 & 0.699 \\
\hline & & $A_{\mathrm{R}}^{\mathrm{E}}$ & 6.00 & 9.88 & 11.00 & 9.82 & 9.87 & 9.74 & 7.88 & 8.00 & 12.63 & 7.88 & 9.27 \\
\hline & & $f^{\mathrm{R}}$ & 0.030 & -0.015 & 0.058 & 0.057 & 0.018 & 0.005 & -0.080 & 0.029 & 0.084 & 0.103 & 0.029 \\
\hline & \multirow[t]{5}{*}{2007} & $N_{\mathrm{A}}$ & 9.00 & 11.00 & 11.00 & 9.00 & 10.00 & 7.00 & 6.00 & 6.00 & 12.00 & 11.00 & 9.20 \\
\hline & & $H_{\mathrm{O}}^{\mathrm{A}}$ & 0.573 & 0.738 & 0.772 & 0.536 & 0.646 & 0.769 & 0.744 & 0.522 & 0.707 & 0.706 & 0.671 \\
\hline & & $H_{\mathrm{E}}^{0}$ & 0.682 & 0.685 & 0.770 & 0.576 & 0.685 & 0.744 & 0.685 & 0.565 & 0.764 & 0.779 & 0.694 \\
\hline & & $A_{\mathrm{R}}$ & 8.52 & 10.43 & 10.94 & 8.72 & 9.57 & 6.87 & 5.84 & 6.00 & 11.47 & 10.59 & 8.89 \\
\hline & & $f^{\mathrm{R}}$ & 0.161 & -0.078 & -0.002 & 0.070 & 0.057 & -0.034 & -0.087 & 0.077 & 0.075 & 0.094 & 0.032 \\
\hline & \multirow[t]{5}{*}{2008} & $N_{\mathrm{A}}$ & 9.00 & 10.00 & 11.00 & 7.00 & 8.00 & 8.00 & 8.00 & 7.00 & 12.00 & 12.00 & 9.20 \\
\hline & & $H_{\mathrm{O}}^{\mathrm{A}}$ & 0.711 & 0.644 & 0.800 & 0.413 & 0.732 & 0.837 & 0.675 & 0.564 & 0.727 & 0.622 & 0.673 \\
\hline & & $H_{\mathrm{E}}$ & 0.721 & 0.780 & 0.741 & 0.447 & 0.642 & 0.740 & 0.685 & 0.543 & 0.753 & 0.810 & 0.680 \\
\hline & & $A_{\mathrm{R}}^{\mathrm{E}}$ & 8.70 & 9.45 & 10.18 & 5.67 & 7.90 & 7.81 & 7.95 & 5.00 & 11.51 & 11.42 & 8.56 \\
\hline & & $f^{\mathrm{R}}$ & 0.014 & 0.093 & -0.080 & 0.077 & -0.142 & -0.133 & 0.015 & -0.039 & 0.034 & 0.234 & 0.007 \\
\hline \multirow[t]{15}{*}{ Wych } & \multirow[t]{5}{*}{2006} & $N_{\mathrm{A}}$ & 5.00 & 7.00 & 7.00 & 7.00 & 8.00 & 7.00 & 7.00 & 5.00 & 7.00 & 9.00 & 6.90 \\
\hline & & $H_{\mathrm{o}}^{\mathrm{A}}$ & 0.806 & 0.694 & 0.906 & 0.714 & 0.771 & 0.706 & 0.571 & 0.821 & 0.944 & 0.861 & 0.780 \\
\hline & & $H_{\mathrm{E}}$ & 0.741 & 0.606 & 0.686 & 0.648 & 0.673 & 0.723 & 0.547 & 0.760 & 0.773 & 0.744 & 0.693 \\
\hline & & $A_{\mathrm{R}}^{\mathrm{E}}$ & 5.00 & 6.54 & 6.50 & 6.36 & 7.19 & 6.61 & 6.16 & 5.00 & 6.77 & 8.44 & 6.46 \\
\hline & & $f^{\mathrm{R}}$ & -0.088 & -0.148 & -0.329 & -0.104 & -0.148 & 0.024 & -0.045 & -0.082 & -0.226 & -0.160 & -0.132 \\
\hline & \multirow[t]{5}{*}{2007} & $N_{\mathrm{A}}$ & 8.00 & 7.00 & 6.00 & 7.00 & 8.00 & 5.00 & 7.00 & 6.00 & 8.00 & 11.00 & 7.30 \\
\hline & & $H_{\mathrm{O}}^{\mathrm{A}}$ & 0.758 & 0.769 & 0.750 & 0.800 & 0.811 & 0.710 & 0.750 & 0.567 & 0.750 & 0.800 & 0.746 \\
\hline & & $H_{\mathrm{E}}^{0}$ & 0.689 & 0.666 & 0.633 & 0.643 & 0.593 & 0.679 & 0.781 & 0.650 & 0.738 & 0.602 & 0.667 \\
\hline & & $A_{\mathrm{R}}$ & 7.73 & 6.71 & 5.83 & 6.43 & 7.62 & 4.97 & 6.81 & 4.00 & 7.25 & 10.18 & 6.75 \\
\hline & & $f^{\mathrm{K}}$ & 0.040 & -0.158 & -0.188 & -0.248 & -0.023 & -0.046 & 0.040 & 0.131 & -0.016 & 0.039 & -0.037 \\
\hline & \multirow[t]{5}{*}{2008} & $N_{\mathrm{A}}$ & 6.00 & 5.00 & 6.00 & 6.00 & 6.00 & 5.00 & 6.00 & 7.00 & 8.00 & 8.00 & 6.30 \\
\hline & & $H_{\mathrm{O}}^{\mathrm{A}}$ & 0.524 & 0.700 & 0.032 & 0.591 & 0.667 & 0.700 & 0.571 & 0.041 & 0.455 & 0.842 & 0.512 \\
\hline & & $H_{\mathrm{E}}$ & 0.777 & 0.533 & 0.528 & 0.569 & 0.779 & 0.613 & 0.751 & 0.542 & 0.659 & 0.658 & 0.641 \\
\hline & & $A_{\mathrm{R}}^{\mathrm{E}}$ & 5.99 & 4.70 & 2.81 & 3.76 & 5.94 & 4.70 & 5.81 & 3.00 & 7.04 & 7.89 & 5.16 \\
\hline & & $f^{\mathrm{K}}$ & 0.331 & -0.323 & 0.284 & -0.040 & 0.148 & -0.147 & 0.244 & 0.135 & 0.315 & 0.019 & 0.097 \\
\hline
\end{tabular}

$\overline{N_{\mathrm{A}}}=$ numbers of alleles; $H_{\mathrm{O}}=$ observed and $H_{\mathrm{E}}=$ expected heterozygosities; $A_{\mathrm{R}}=$ allelic richness; $f=$ inbreeding coefficient. Bold values indicate a significant $(\mathrm{P}<0.05)$ deviation from Hardy-Weinberg equilibrium (HWE); however, none of the tests remained significant after a sequential Bonferroni's correction for $k=3$.

At both sites, no significant genetic differences were attributed to variation among temporal groups of samples $(\mathrm{P}>0.05)$, which accounted for between 2 to $3 \%$ of the total genetic variance (Table S1).

\section{Movement tendency}

There was genetic evidence for male-biased movement in adults at both sites, which was consistent with the direct estimates of movement tendencies identified from the nestbox surveys of chipped animals. Thus, average relatedness, $r$, was significantly $(\mathrm{P}<0.05)$ lower in adult males than in adult females in both populations, and significantly negative $m A I c$ and greater values of $v A I C$ and $F_{\text {IS }}$ were observed in males than in females (Table 2 and Table S2). We also found qualitative evidence of male-biased movement by juveniles at Bontuchel ( $\mathrm{N}$ $=50)$ and Wych $(\mathrm{N}=15)$, whereby the values of $m A I c$ and $v A I c$ were respectively lower and higher in males, but differences between male and female juveniles were not significant, probably because of the small sample size or because of a mixture of pre- and post-movement of juvenile males (Table 2). 


\begin{tabular}{|c|c|c|c|c|c|c|}
\hline & \multicolumn{3}{|c|}{ Bontuchel } & \multicolumn{3}{|c|}{ Wych } \\
\hline & Female $\mathrm{N}=138$ & Male $\mathrm{N}=108$ & $\mathrm{P}$ & Female $\mathrm{N}=67$ & Male $N=53$ & $\mathrm{P}$ \\
\hline$F_{\text {IS }}$ & 0.018 & 0.064 & $<0.05$ & -0.012 & 0.055 & $<0.05$ \\
\hline$m A I c$ & 0.192 & -0.155 & $<0.05$ & 0.048 & -0.029 & $<0.05$ \\
\hline$v A I c$ & 16.434 & 21.006 & $<0.05$ & 6.364 & 13.46 & $<0.05$ \\
\hline$r$ & 0.334 & 0.327 & $<0.05$ & 0.254 & 0.054 & $<0.05$ \\
\hline$H_{\mathrm{S}}$ & 0.694 & 0.649 & & 0.714 & 0.732 & \\
\hline
\end{tabular}

See Material and Methods section for definitions of $F_{\mathrm{IS}}, H_{\mathrm{S}}, r, m A I c, v A I c$; P values indicate significance of statistical tests and were generated by 10,000 randomisations.

\section{Spatial genetic structure}

Individual correlogram profiles of the relationship between average kinship $\left(F_{\mathrm{IJ}}\right)$ and spatial separation varied slightly between sampling years, but any differences were not significant as the $95 \%$ confidence intervals for the average value of $F_{\mathrm{IJ}}$ at each distance class overlapped. Therefore, the data are presented as an average over all years (but with pairwise estimates of $F_{\mathrm{IJ}}$ restricted to individuals from the same sample year) to demonstrate the broad pattern of movement behaviour. Thus, a significant pattern of spatial autocorrelation was observed in adult females at both sites, with pairs of individuals up to $200 \mathrm{~m}$ apart having significant $F_{\mathrm{IJ}}$ values and then significantly negative $F_{\mathrm{IJ}}$ values from $300 \mathrm{~m}$ and beyond (Figure 2). Consistent with the analyses described above indicating male-biased movement, a contrast in the pattern of spatial genetic structuring between adult males and females was evident in both populations. Adult males at both sites displayed lower levels of relatedness at short distance classes (Figure 2), and only average $F_{\mathrm{IJ}}$ at 500-m distance classes was significantly different from zero. Generally, the $F_{\mathrm{IJ}}$ values for adult dormice at Bontuchel were consistently higher than at Wych but the difference was not significant ( $t$-test, $t=1.32$, d.f. $=16, \mathrm{P}>0.05)$; this pattern was also observed in juveniles at both sites $(t$-test, $t=1.06$, d.f. $=16, \mathrm{P}>0.05)$.

Assignment tests revealed a relatively low rate of immigration and supported the idea of male-biased movement, with a high proportion of individuals $(95.5 \%$ of the 246 adults at Bontuchel and $92.5 \%$ of the 120 adults at Wych) likely to be residents (at $>95 \%$ likelihood). There were 11 individuals ( 9 males, 2 females) and nine individuals ( 6 males, 3 females) at Bontuchel and Wych, respectively, assigned as potential immigrants $(\mathrm{P}<0.05$; data pooled over years), although none of these individuals were identified as suspected immigrants at a more stringent probability of $\mathrm{P}<0.01$.

\section{DISCUSSION}

The main outcomes of this study are that, using the combination of direct observation and molecular genetics technique, 1) a natural pattern of movement is maintained in the reintroduced population founded with individuals from a captive breeding programme, and 2) common dormice are relatively sedentary but exhibit sex-biased movement, with adult males dispersing further than females. We present evidence for lower genetic diversity in the reintroduced population compared with a natural site, but there was no significant bottleneck effect. Moreover, while there is no evidence for strong spatial structure that is manifest as discrete subpopulations within these relatively large habitat patches, movement is sufficiently limited to allow isolation by distance genetic structure to develop. 


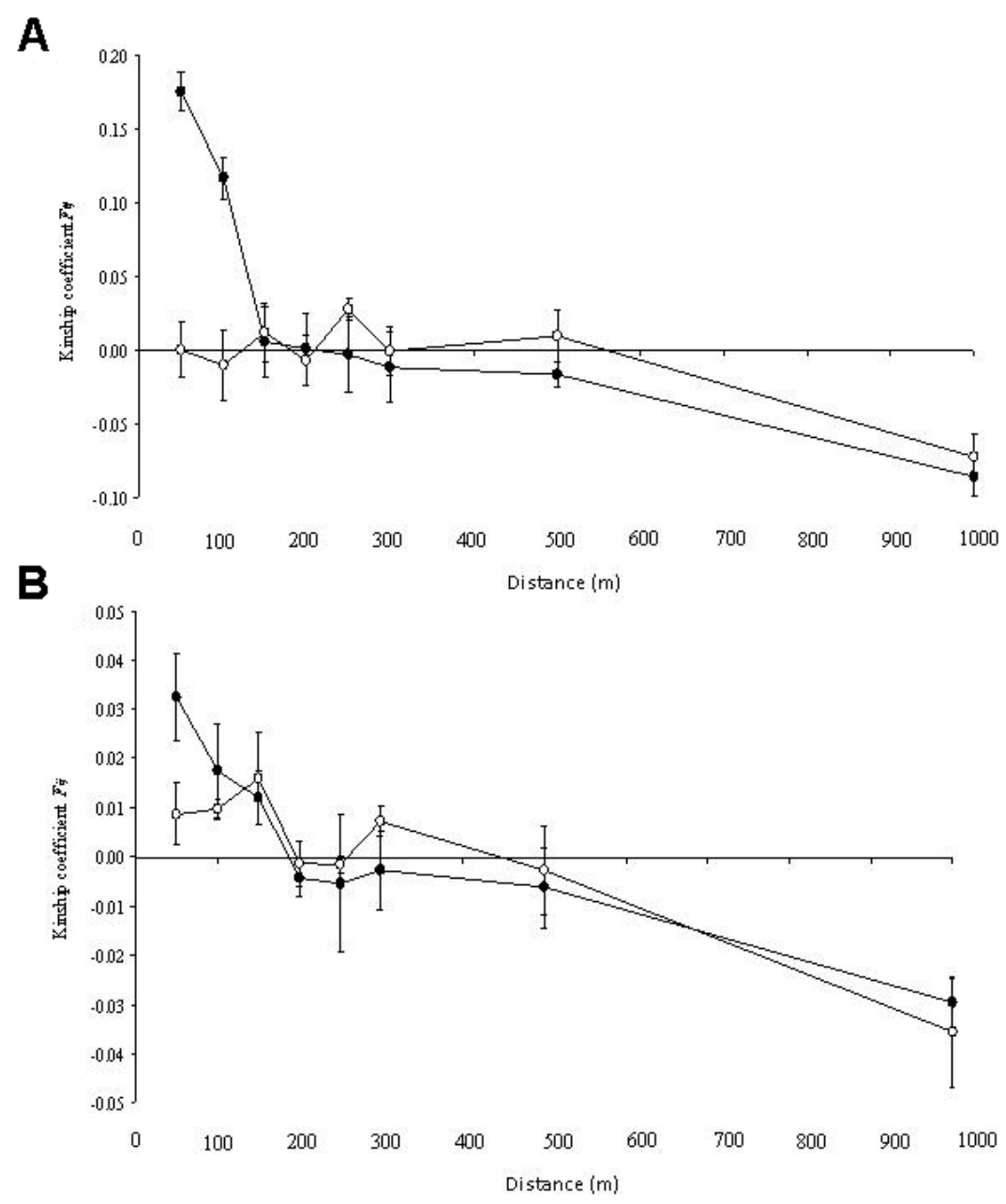

Figure 2. Spatial variation in average kinship $\left(F_{\mathrm{IJ}}\right)$ (Loiselle et al., 1995) among pairs of adult males (open circles) and adult females (filled circles) of Muscardinus avellanarius in A. Bontuchel and B. Wych. Standard errors were obtained by jackknifing over 10 microsatellite loci.

\section{Movement behaviour}

Similarities in both the scale of movement and pattern of male-biased movement evident (using both direct and indirect measurements) at both sites indicated that a period of captive breeding did not affect movement behaviour. This result is contrary with a study conducted by McPhee (2003), in which a period of captivity apparently compromised the behaviour of oldfield mice Peromyscus polionotus; likewise, other studies have demonstrated the failure of captive bred animals in retaining their natural behaviour when released into the wild (see Fischer and Lindenmayer, 2000; Hellstedt and Kallio, 2005; Kelley et al., 2006, for review).

Partitioning the patterns of genetic differentiation for each sex separately is a crucial part of understating a species' ecology. In this study, the propensity of tagged adult males to 
move further than a female (Figure 1) is consistent with the genetic data (Figure 2 and Table 2), and give more empirical support to notion that the greater movements made by males (combining both natal dispersal and subsequent movements as breeding adults) translates into the movement of genes. The agreement between direct and indirect methods of quantifying movement in our study supports a recent conclusion that individual-level genetic data can be useful in determining movement distances for species that lack direct estimates for movement, particularly when movement has been studied within continuous habitat patches (Broquet et al., 2006; Watts et al., 2007; Selonen et al., 2010). However, studies at larger spatial scales often detect more frequent and longer movement events using indirect than by direct approaches (see Telfer et al., 2003), and thus, genetic studies should be employed for studies of movement by dormice at wider spatial scales.

\section{Spatial genetic structure}

Spatially limited movement causes an increase in genetic differentiation among individuals separated by increasing geographic distances (Rousset, 1997). We found isolation-bydistance (IBD) (Figure 2) developing within $1 \mathrm{~km}$, a scale similar to other mammal species (e.g., Hazlitt et al., 2004; Schweizer et al., 2007; Busch et al., 2009), which is driven by a combination of broadly quite-limited movement distances and particularly female philopatry. Interestingly, the qualitative contrast in the level of kinship of female dormice at the smallest distance class between Bontuchel and Wych (Figure 2) may be a feature of the reintroduction. Thus, local groups of females at Wych appeared to have a greater proportion of unrelated females than at Bontuchel. With time, however, female philopatry and variance in reproductive success may drive the local breeding units to constitute greater proportions of related females. Further comparisons between natural and reintroduced populations are required to examine this in more detail. Nevertheless, no significant subpopulations were detected by AMOVA (Table S1) or Bayesian clustering techniques (data not shown), suggesting that rate and pattern of (certainly male) movement is sufficient to prevent the formation of discrete subpopulations in continuous habitat patches of more than $0.5 \mathrm{~km}^{2}$.

That fewer immigrant females than males were identified in both populations lend further support to the patterns of male-biased movement discussed above. The greater proportion of male versus female immigrants was also detected in our study in the patterns of genetic divergence between populations of the common dormouse in the UK (Naim et al., 2012). Moreover, the possibility of immigrant dormice at both sites is intriguing given this species' conservation status. Evidence of dormice inhabiting parts of the surrounding area at Bontuchel (Jones, 2007) that could serve as potential source patches, implies that dormice occasionally move further than $1 \mathrm{~km}$, and across inhospitable agricultural habitat (although likely using hedgerows as corridors) (Büchner, 2008; Juškaitis, 2008). Potential immigrants at Wych raise the possibility of neighbouring dormice populations, and indeed, these immigrants may have augmented the genetic diversity of the reintroduced Wych population. Alternatively, the suspected immigrants may reflect the genetic structure of the mixed population origins of the individuals used for captive breeding.

\section{Patterns of genetic diversity}

Almost certainly because of the relatively small number of founders, the reintroduced 
population at Wych harbours less genetic diversity than the population at Bontuchel (Table 1). Indeed, many populations established from a limited number of founders typically show a reduction in genetic variability compared with more established, natural populations (Fitzsimmons et al., 1997; Sigg, 2006). Nonetheless, that there was no significant difference in gene diversity $\left(H_{\mathrm{E}}\right)$ between sites points towards a relatively limited extent of genetic erosion at Wych. One likely reason for this is the prevalence of multiple mating by female dormice that prevents one or few males from dominating the genetic make-up of the population (Naim et al., 2011). In addition, a high survival rate of the reintroduced animals will limit any loss of diversity. Certainly, the majority of common dormice reintroductions have been apparently successful as indicated by high survival rates after the first hibernation and subsequent establishment of breeding populations (Morris, 2004; Mitchell-Jones and White, 2009). Our genetic data support this - the Wych population is genetically diverse and there is no evidence that it has passed through a significant population bottleneck. Likewise, the population at Bontuchel has not recently undergone an apparent significant reduction in size, although it has to be noted that any homozygote excess is maintained for just $2 N_{\mathrm{e}}-4 N_{\mathrm{e}}$ generations after the bottleneck event (Piry et al., 1999).

\section{CONCLUSION}

Despite its high conservation profile, it is surprising that to date no study has determined the pattern and extent of spatial genetic structure using molecular genetic techniques in common dormice, despite the considerable effort that has been directed towards habitat management, captive breeding and reintroductions. By comparing the wild dormouse population and the reintroduced population that was established from a captive bred population, this study demonstrated how aspects of a species' behaviour (particularly movement) can generate a population genetic structure over a small geographical scale (less than $1 \mathrm{~km}$ ) in continuous habitat patches with gene flow largely mediated by short movement distance by males. This short movement behaviour has important implications for the conservation of the species, where it can increase considerably the vulnerability of populations to extinction. However, the detection of some immigrants at both population sites and documented report of a long distance moved by marked juveniles (i.e., more than $1 \mathrm{~km}$ ) (Büchner, 2008; Juškaitis, 2008; Juškaitis and Büchner, 2010) would appear to have increased genetic diversity, and as such, genetic monitoring may be used to identify new dormouse populations. Since there is evidence of sex-biased movement and that reintroduced dormice retain their natural movement behaviour, in the future, it would be useful for managers of reintroduction efforts to consider the spatial aspects and the sex ratio of released animals. Obviously, further studies on additional populations are required to explore the consequences of these findings in more detail.

\section{ACKNOWLEDGMENTS}

Research supported by the Malaysian Government and Universiti Sains Malaysia (USM) for Academic Staff Training Scheme (ASTS). We thank all of the members of the Northwest Dormouse Partnership, particularly Scott Wilson, Rhian Hughes and Iolo Lloyd and the Forestry Commission, as well as all of the volunteers who helped during survey work. 


\section{Supplementary material}

\section{REFERENCES}

Armstrong DP and Seddon PJ (2008). Directions in reintroduction biology. Trends Ecol. Evol. 23: 20-25.

Ausband D and Moehrenschlager A (2009). Long-range juvenile dispersal and its implication for conservation of reintroduced swift fox Vulpes velox populations in the USA and Canada. Oryx 43: 73-77.

Bowkett AE (2009). Recent captive-breeding proposals and the return of the ark concept to global species conservation. Conserv. Biol. 23: 773-776.

Bright P and Morris P (1992). The Dormouse. The Mammal Society, London.

Bright PW, Morris PA and Mitchell JT (2006). The Dormouse. Conservation Handbook. 2nd edn. English Nature, Peterborough.

Broquet T and Petit EJ (2009). Molecular estimation of dispersal for ecology and population genetics. Annu. Rev. Ecol. Evol. Systemat. 40: 193-216.

Broquet T, Johnson CA, Petit E, Thompson I, et al. (2006). Dispersal and genetic structure in the American marten, Martes americana. Mol. Ecol. 15: 1689-1697.

Bryant EH and Reed DH (1999). Fitness decline under relaxed selection in captive populations. Conserv. Biol. 13: 665-669.

Busch JD, Waser PM and DeWoody JA (2009). The influence of density and sex on patterns of fine-scale genetic structure. Evolution 63: 2302-2314.

Büchner S (2008). Dispersal of common dormice Muscardinus avellanarius in a habitat mosaic. Acta Theriol. 53: 259-262.

Clobert J, Danchin E, Dhondt AA and Nichols JD (2001). Dispersal: Individual, Population and Community. Oxford University Press, England.

Diefenbach DR, Hansen LA, Warren RJ and Conroy MJ (2006). Spatial organization of a reintroduced population of bobcats. J. Mammal. 87: 394-401.

Ewing SR, Nager RG, Nicoll MA, Aumjaud A, et al. (2008). Inbreeding and loss of genetic variation in a reintroduced population of Mauritius Kestrel. Conserv. Biol. 22: 395-404.

Excoffier L, Smouse PE and Quattro JM (1992). Analysis of molecular variance inferred from metric distances among DNA haplotypes: application to human mitochondrial DNA restriction data. Genetics 131: 479-491.

Fischer J and Lindenmayer DB (2000). An assessment of the published results of animal relocations. Biol. Conserv. 96: $1-11$.

Fitzsimmons NN, Buskirk SW and Smith MH (1997). Genetic changes in reintroduced Rocky Mountain bighorn sheep populations. J. Wildl. Manage. 61: 863-872.

Frankham R (2008). Genetic adaptation to captivity in species conservation programs. Mol. Ecol. 17: 325-333.

Goudet J (2001). FSTAT, A Program to Estimate and Test Gene Diversities and Fixation Indices (Version 2.9.3). Available at [http://www.unil.chlizea/softwares/fstat.html]. Accessed June 18, 2012.

Goudet J, Perrin N and Waser P (2002). Tests for sex-biased dispersal using bi-parentally inherited genetic markers. Mol. Ecol. 11: 1103-1114.

Grenier MB, McDonald DB and Buskirk SW (2007). Rapid population growth of a critically endangered carnivore. Science 317: 779.

Hanski I (1999). Habitat connectivity, habitat continuity and metapopulaitons in dynamics landscapes. Oikos 87: 209-219.

Hardy OJ and Vekemans X (1999). Isolation by distance in a continuous population: reconciliation between spatial autocorrelation analysis and population genetics models. Heredity 83: 145-154.

Hardy OJ and Vekemans X (2002). Spagedi: a versatile computer program to analyse spatial genetic structure at the individual or population levels. Mol. Ecol. Notes 2: 618-620.

Hazlitt SL, Eldridge MD and Goldizen AW (2004). Fine-scale spatial genetic correlation analyses reveal strong female philopatry within a brush-tailed rock-wallaby colony in southeast Queensland. Mol. Ecol. 13: 3621-3632.

Hellstedt P and Kallio ER (2005). Survival and behaviour of captive-born weasels (Mustela nivalis nivalis) released in nature. J. Zool. 266: 37-44.

IUCN (2009). European Mammal Assessment. Available at [http://www.iucnredlist.org/apps/redlist/search]. Accessed October 11, 2010.

Jones AL (2007). Bontuchel Woods Dormouse Project. Dormouse Monitor. PTES, London.

Juškaitis R (2001). Weight changes of the common dormouse (Muscardinus avellanarius L.) during the year in Lithuania. Trakya Univ. J. Sci. Res. Ser. B 2: 79-83.

Juškaitis R (2005). Daily torpor in free-ranging common dormice (Muscardinus avellanarius) in Lithuania. Mammal. Biol. 70: 242-249. 
Juškaitis R (2008). The Common Dormouse Muscardinus avellanarius: Ecology, Population Structure and Dynamics. Institute of Ecology of Vilnius University Publishers, Vilnius.

Juškaitis R and Büchner S (2010). Dormouse. Westarp Wissenschaften, Magdeburg.

Kelley JL, Magurran AE and Garcia CM (2006). Captive breeding promotes aggression in an endangered Mexican fish. Biol. Conserv. 133: 169-177.

Koenig WD, Van Vuren D and Hooge PN (1996). Detectability, philopatry, and the distribution of dispersal distances in vertebrates. Trends Ecol. Evol. 11: 514-517.

Lawson Handley LJ and Perrin N (2007). Advances in our understanding of mammalian sex-biased dispersal. Mol. Ecol. 16: 1559-1578.

Lidicker JWZ and Patton JL (1987). Patterns of Dispersal and Genetic Structure in Populations of Small Rodents. In: Mammalian Dispersal Pattern: The Effects of Social Structure on Population Genetics (Chepko-Sade BD and Halpin ZT, eds.). University of Chicago Press, Chicago.

Loiselle BA, Sork VL, Nason J and Graham C (1995). Spatial genetic-structure of a tropical understory shrub, Psychotria officinalis (Rubiaceae). Am. J. Bot. 82: 1420-1425.

Lynch M and Ritland K (1999). Estimation of pairwise relatedness with molecular markers. Genetics 152: 1753-1766.

Manel S, Schwartz M, Luikart G and Taberlet P (2003). Landscape genetics: combining landscape ecology and population genetics. TREE 18: 189-206.

McPhee ME (2003). Generations in captivity increases behavioural variance: considerations for captive breeding and reintroduction programs. Biol. Conserv. 115: 71-77.

Mitchell-Jones AJ and White I (2009). Using reintroductions to reclaim the lost range of the dormouse Muscardinus avellanarius, in England. Folia Zool. 58: 341-348.

Morris PA (2004). Dormice. British Natural History Series. Whittet Books Ltd., Suffolk.

Naim DM, Kemp SJ, Telfer S and Watts PC (2009). Isolation and characterization of 10 microsatellite loci in the common dormouse Muscardinus avellanarius. Mol. Ecol. Res. 9: 1010-1012.

Naim DM, Telfer S, Sanderson S, Kemp SJ, et al. (2011). Prevalence of multiple mating by female common dormice, Muscardinus avellanarius. Conserv. Genet. 12: 971-979.

Naim DM, Telfer S, Tatman S, Bird S, et al. (2012). Patterns of genetic divergence among populations of the common dormouse, Muscardinus avellanarius in the UK. Mol. Biol. Rep. 39: 1205-1215.

Neveu H, Hafen T, Zimmermann E and Rumpler Y (1998). Comparison of the genetic diversity of wild and captive groups of Microcebus murinus using the random amplified polymorphic DNA method. Folia Primatol. 69 (Suppl 1): $127-135$.

Paetkau D, Slade R, Burden M and Estoup A (2004). Genetic assignment methods for the direct, real-time estimation of migration rate: a simulation-based exploration of accuracy and power. Mol. Ecol. 13: 55-65.

Piry S, Luikart G and Cornuet JM (1999). BOTTLENECK: A computer program for detecting recent reductions in the effective population size using allele frequency data. J. Hered. 90: 502-503.

Piry S, Alapetite A, Cornuet JM, Paetkau D, et al. (2004). GENECLASS2: A software for genetic assignment and firstgeneration migrant detection. J. Hered. 95: 536-539.

Ralls K, Ballou JD and Templeton A (1988). Estimates of lethal equivalents and the cost of inbreeding in mammals. Conserv. Biol. 2: 185-193.

Raymond M and Rousset F (1995). GENEPOP (version 1.2): Population genetics software for exact tests and ecumenism. J. Hered. 86: 248-249.

Rice WR (1989). Analyzing tables of statistical tests. Evolution 43: 223-225.

Robert A (2009). Captive breeding genetics and reintroduction success. Biol. Conserv. 142: 2915-2922.

Rousset F (1997). Genetic differentiation and estimation of gene flow from F-statistics under isolation by distance. Genetics 145: 1219-1228.

Saccheri I, Kuussaari M and Kankare M (1998). Inbreeding and extinction in a butterfly metapopulation. Nature 392: 491-494.

Schneider S, Roessli D and Excoffier L (2000). Arlequin: A Software for Population Genetics Data Analysis. Genetics and Biometry Laboratory, Department of Anthropology, University of Geneva, Switzerland. Available at [http://lgb. unige.ch/arlequin/]. Accessed June 19, 2012.

Schweizer M, Excoffier L and Heckel G (2007). Fine-scale genetic structure and dispersal in the common vole (Microtus arvalis). Mol. Ecol. 16: 2463-2473.

Scribner T, Blanchong JA, Bruggeman DJ, Epperson B, et al. (2006). Geographical genetics: conceptual foundations and empirical applications of spatial genetic data in wildlife management. J. Wildl. Manage. 70: 1434-1453.

Selonen V, Hanski IK and Painter JN (2010). Gene flow and natal dispersal in the Siberian flying squirrel based on direct and indirect data. Conserv. Genet. 11: 1257-1264. 
Sigg DP (2006). Reduced genetic diversity and significant genetic differentiation after translocation: Comparison of the remnant and translocated populations of bridled nailtail wallabies. Conserv. Genet. 7: 577-589.

Telfer S, Dallas JF, Aars J, Piertney SB, et al. (2003). Demographic and genetic structure of fossorial water voles (Arvicola terrestris) on Scottish islands. J. Zool. 259: 23-29.

Van Oosterhout C, Hutchinson WF, Wills DPM and Shipley P (2004). MICRO-CHECKER: software for identifying and correcting genotyping errors in microsatellite data. Mol. Ecol. Notes 4: 535-538.

Walsh PS, Metzger DA and Higuchi R (1991). Chelex 100 as a medium for simple extraction of DNA for PCR-based typing from forensic material. Biotechniques 10: 506-513.

Watts PC, Rousset F, Saccheri IJ, Leblois R, et al. (2007). Compatible genetic and ecological estimates of dispersal rates in insect (Coenagrion mercuriale: Odonata: Zygoptera) populations: analysis of 'neighbourhood size' using a more precise estimator. Mol. Ecol. 16: 737-751.

Weir BS and Cockerham CC (1984). Estimating F-statistics for the analysis of population structure. Evolution 38: 13581370.

Wright S (1951). The genetical structure of populations. Ann. Eugen. 15: 323. 